\title{
Further Studies on Corynebacterium Species Capable of Producing Diphtheria Toxin (C. diphtheriae, C. ulcerans, C. ovis)
}

\author{
By PAULA MAXIMESCU, ALIS OPRIŞAN, A. POP AND \\ E. POTORAC
}

Dr I. Cantacuzino Institute, Bucharest, Romania

(Received I5 May 1973; revised 6 September 1973)

\begin{abstract}
SUMMARY
Lysogenization experiments showed that diphtheria phages can induce the production of diphtheria toxin in strains of Corynebacterium ulcerans and $C$. ovis. In addition to diphtheria toxin, lysogenic $C$. ulcerans and $C$. ovis strains each produce their own specific toxin; they also maintain their specific morphology and urease production whilst $C$. diphtheriae strains lysogenized by $C$. ulcerans phages produce only diphtheria toxin. The majority of $C$.ulcerans phages are unable to induce the production of diphtheria toxin in strains of $C$. ulcerans.

Phage typing with Corynebacterium ulcerans phages is a practical possibility. Thirteen well-defined phage types were established by this technique in $172 C$. ulcerans and 62 C. ovis strains with only one of the phage types (IIIC) occurring in both species. C. ulcerans can be distinguished from $C$. ovis by the pathogenicity test in mice. $C$. ovis kills mice by any route of inoculation whilst $C$. ulcerans strains cause only arthritis. $C$. ulcerans wild strains could be identified in this way and C. ulcerans and C. ovis strains from different type culture collections could be distinguished from each other by these well-defined characteristics.
\end{abstract}

\section{INTRODUCTION}

The somewhat surprising capacity of strains of Corynebacterium ovis to produce diphtheria toxin as a consequence of lysogenization with a diphtheria phage has led to further investigation of some of the biological characters of the three Corynebacterium species able to produce diphtheria toxin. These species are C. diphtheriae (C.D.), C. ulcerans (C.U.) and C. ovis (C.O.).

Earlier investigations of the characteristics of Corynebacterium ulcerans (Stănică et al. 1968; Maximescu, I967; I968) enabled us to collect a number of strains of this species during routine tests of diphtheria cases and carriers. According to many authors the differentiation between the species $C$. diphtheriae, C. ulcerans and C. ovis is not very precise, particularly as we found that they share some common characteristics, such as hydrolysis of cystine, sugar fermentations (according to either the gravis, the mitis or the intermedius patterns) and release of diphtheria toxin. Since we described the production of diphtheria toxin by lysogenized $C$. ovis strains (Maximescu, Pop, Oprişan \& Potorac, 1968) it seemed important to investigate further the phage-host relationships in strains of $C$. ulcerans, $C$. ovis and $C$. diphtheriae in an attempt to improve the characterization of these species and their classification.

The four different aspects investigated were: (i) lysogenization; (ii) attempts at phagetyping strains of Corynebacterium ulcerans and $C$. ovis with a set of $C$. ulcerans phages; 
(iii) evaluation of the mouse pathogenicity test for the differentiation of $C$. ulcerans from $C$. ovis; and (iv) a survey of a larger number of wild- and type-collection strains of C. ulcerans and $C$. ovis from an epidemiological point of view.

\section{METHODS}

Corynebacterium strains. Wild Corynebacterium ulcerans strains were isolated in Romania: 4 strains from human sore throats, 122 strains from human carriers, and 35 strains from the rhinopharyngeal flora of normal horses. Among these strains were 298G, 9304, 40c, A238 and 775, mentioned elsewhere in this paper, most of which were kindly supplied by our Romanian colleagues from Public Health Laboratories.

Collection strains of Corynebacterium ulcerans. The following strains were kindly supplied by Professor H. R. Carne of Cambridge (see Carne, I 968): u. 25908, u. 26346, and u. 26348, originating from N.S. Mair; no. I starch-fermenting and no. 2 non-starch-fermenting, originating from W. H. H. Jebb (see Jebb, I948, and Jebb \& Martin, I965); and $u_{1} .2972 / 49$, $u_{4} .1254 / 50, u_{5} .1605 / 50, u_{6} .1661 / 50$ and $u .976 / 5 I$, originating from S. D. Henriksen (see Henriksen, 1955). Strains $u_{3} .892 / 50,389 / 53$ and $355 / 53$ were kindly supplied by Professor S. D. Henriksen, Oslo, Norway, and I6L supplied by the late Professor D. T. Robinson and Dr E. C. Armstrong, Liverpool.

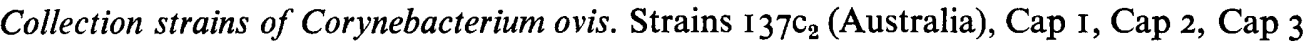
(Ayoub, Egypt), Bov I, Bov 2 (Zaki, Egypt), I I33, I 34 (Australia), I I 23, 1 I 24 (U.S.A.), and II29, II30 (Kenya), were all kindly supplied by Professor H. R. Carne, Cambridge; C. ovis A (Australia) was kindly supplied by Dr M. Battey, Brisbane, Australia (see Battey, Tonge, Horsfall \& McDonald, I968); C. ovis $\mathrm{T}$ was received from $\mathrm{Dr}$ Afnan, Teheran, Iran (see Afnan, I969); ten C. ovis strains were received from Dr M. Zaki, Assiut, Egypt; C. ovis 20 and 2I (Zaki) were supplied by Professor N. Stamatin, Bucharest, Romania; also a further 40 strains from collections.

All strains were also given registered numbers at our laboratory (see column I, Table I).

Corynebacterium diphtheriae strains. $\mathrm{I030}_{(-)}{ }^{\text {tox }^{-}} C$. belfanti (Maximescu, I968) and $5056_{(-)}{ }^{\text {tox }}{ }^{-}$C.D. intermedius.

All strains were either lyophilized or kept at room temperature on Loeffler slopes.

Media. (i) For phage typing: I.5\% heart-brain agar (Narbutovicz, 1955) with $0.001 \%$ cystine and $10 \%$ normal ox serum (Saragea \& Maximescu, 1964). (ii) For phage multiplication: heart broth with $0.001 \%$ cystine. (iii) For production of diphtheria toxin: Pope-Linggood broth with $0.6 \%$ maltose and I \% sodium acetate (Saragea \& Maximescu, I964); for production of ovis and ulcerans toxin: heart broth with $0.6 \%$ maltose and $\mathrm{I} \%$ sodium acetate.

Toxigenicity. The presence of diphtheria toxin was demonstrated by skin tests on rabbits (Fraser, I93I), guinea-pig inoculation by the Elek agar gel diffusion method as modified by Maximescu \& Drăgoi (197I), and in monkey kidney tissue culture (Calalb et al. 1965).

Pathogenicity test. White mice (strain NMRI, 16 to $18 \mathrm{~g}$ weight, irrespective of sex) were injected intravenously with $0.1 \mathrm{ml}$ of a 24 to $48 \mathrm{~h}$ broth culture of either Corynebacterium ulcerans or C. ovis.

Bacteriophages. (i) Corynebacterium diphtheriae phages: W (PW8 phage, Maximescu, I968); nos. 2, 20, 2 I and 23 from the set of phages used by Saragea \& Maximescu (1964). (ii) C.ulcerans phages: $15542 / 238$ (a); 213/40 (b); 16259/40 (c); $210 / 16 \mathrm{~L}$ (d); $9304 / 984$ (g) and $984 / 984$ (h). (iii) Phage $76 \mathrm{c}$ is a $C$. diphtheriae phage (originated from the $76 \mathrm{c} \mathrm{C.D.} \mathrm{gravis}$ tox $^{+}$strain) restricted in strain C. ovis $2 \mathrm{I}$. 
Table I. Corynebacterium ulcerans and C. ovis collection strains*

\begin{tabular}{|c|c|c|c|}
\hline $\begin{array}{l}\text { Registered } \\
\text { no. }\end{array}$ & Source & $\begin{array}{l}\text { Diphtheria } \\
\text { toxin }\end{array}$ & $\begin{array}{l}\text { Phage } \\
\text { type }\end{array}$ \\
\hline \multicolumn{4}{|c|}{ Corynebacterium ulcerans } \\
\hline 978 & u. 25908, N. S. Mair, Leicester, Publ. Hlth Lab., 1957 & + & IVD \\
\hline 979 & u. 26346, N. S. Mair, Leicester, Publ. Hlth Lab., 1957 & + & IVD \\
\hline 980 & u. 26348, N. S. Mair, Leicester, Publ. Hlth Lab., 1957 & + & IVD \\
\hline $98 \mathrm{I}$ & $\begin{array}{l}\text { No. I, starch-fermenting, W. H. H. Jebb, Publ. Hlth } \\
\text { Lab., Oxford }\end{array}$ & + & VE \\
\hline 983 & $\begin{array}{l}\text { No. 2, non-starch-fermenting, W. H. H. Jebb, } \\
\text { Publ. Hlth Lab., Oxford }\end{array}$ & + & IVD \\
\hline 982 & u. I, 2972/49, S. D. Henriksen, Oslo, Norway & + & II $B_{2}$ \\
\hline 984 & u.4, I254/50, S. D. Henriksen, Oslo, Norway & + & $\mathbf{A}_{0}$ \\
\hline 985 & u.5. I605/50, S. D. Henriksen, Oslo, Norway & + & IA \\
\hline 986 & u. 6, I66I/5o, S. D. Henriksen, Oslo, Norway & - & $\begin{array}{l}\text { Phage-sensitive, } \\
\text { non-typable }\end{array}$ \\
\hline 987 & u. $8,976 / 5$ I, S. D. Henriksen, Oslo, Norway & + & $\mathbf{A}_{\mathbf{0}}$ \\
\hline 2506 & u. $603 / 50$, S. D. Henriksen, Oslo, Norway & - & IA \\
\hline 2507 & u. $3,892 / 50$, S. D. Henriksen, Oslo, Norway & - & $\mathbf{A}_{0}$ \\
\hline 2508 & u.389/53, S. D. Henriksen, Oslo, Norway & + & IVD \\
\hline 2509 & u. $355 / 53$, S. D. Henriksen, Oslo, Norway & + & $\mathbf{A}_{0}$ \\
\hline $16 \mathrm{~L}$ & $\begin{array}{l}\text { C. ulcerans, D. T. Robinson and E. C. Armstrong, } \\
\text { Liverpool }\end{array}$ & + & IIIC \\
\hline 9304 & C. ulcerans, P. Maximescu, 1968 & - & IA \\
\hline 775 & u. 775, non-starch-fermenting, Romania & + & IVD \\
\hline \multicolumn{4}{|c|}{ Corynebacterium ovis } \\
\hline 988 & I 37 c2, Sydney, Australia, 1950 & - & $\mathrm{VIG}_{2}$ \\
\hline 989 & Cap. I, Dr Ayoub, Egypt, I965 & - & $\mathrm{IIB}_{1}$ \\
\hline 990 & Cap. 2, Dr Ayoub (from Egyptian goat), 1965 & - & II B $_{1}$ \\
\hline $99 \mathrm{I}$ & Cap. 3, Dr Ayoub (from Egyptian goat), 1965 & - & II B $_{1}$ \\
\hline 992 & Bov I, Dr Zaki (from Egyptian buffalo) & + & IIIC \\
\hline 993 & Bov 2, Dr Zaki (from Egyptian buffalo) & + & IIIC \\
\hline 994 & No. I I33, lymph-node abcess in sheep, Australia, 1974 & - & $\mathrm{VIG}_{2}$ \\
\hline 995 & No. I I 34, lymph-node abcess in sheep, Australia, 1974 & - & $\mathrm{VIG}_{2}$ \\
\hline 996 & No. I I 23, pectoris abcess in horse, U.S.A., 1960 & - & II B $_{0}$ \\
\hline 997 & No. I1 24 , pectoris abcess in horse, U.S.A., 1960 & - & $\mathrm{II}_{\mathbf{0}}$ \\
\hline 998 & No. I I 29, ulcerative lymphangitis, Kenya, before 1950 & - & II B $_{0}$ \\
\hline 999 & No. I I 30, ulcerative lymphangitis, Kenya, before 1950 & - & $\mathrm{IIB}_{\mathbf{0}}$ \\
\hline A & C.O. A., Australia, human case & - & $\mathrm{VIG}_{2}$ \\
\hline 20 & $\begin{array}{l}\text { C.O. 2o, Dr Zaki, Professor Stamatin collection, } \\
\text { Bucharest, Romania }\end{array}$ & - & $\mathbf{V I G}_{2}$ \\
\hline 21 & $\begin{array}{l}\text { C.O. 21, Dr Zaki, Professor Stamatin collection, } \\
\text { Bucharest, Romania }\end{array}$ & - & $\mathrm{VIG}_{2}$ \\
\hline $\mathbf{T}$ & C.O. Teheran, Dr Afnan & - & II B $_{0}$ \\
\hline
\end{tabular}

* Strains quoted in the papers of: Afnan (1969); Battey, Tonge, Horsfall \& McDonald (1968); Henriksen (1955); Howard \& Jann (1954); Maximescu (1968).

Phage-typing of Corynebacterium ulcerans and C.ovis strains was performed by the technique described by Saragea \& Maximescu (1964) for $C$. diphtheriae strains.

Throughout this paper diphtheria toxin is referred to as Di-toxin and the strains producing it as $\mathrm{Di}^{\text {tox }}{ }^{+}$.

\section{RESULTS}

\section{Lysogenization experiments}

These were carried out with diphtheria phages in strains of Corynebacterium ulcerans and $C$. ovis, and with $C$. ulcerans phages in strains of $C$. diphtheriae.

Four Corynebacterium ulcerans strains (40c, A238, 298G and 9304) could be lysogenized 

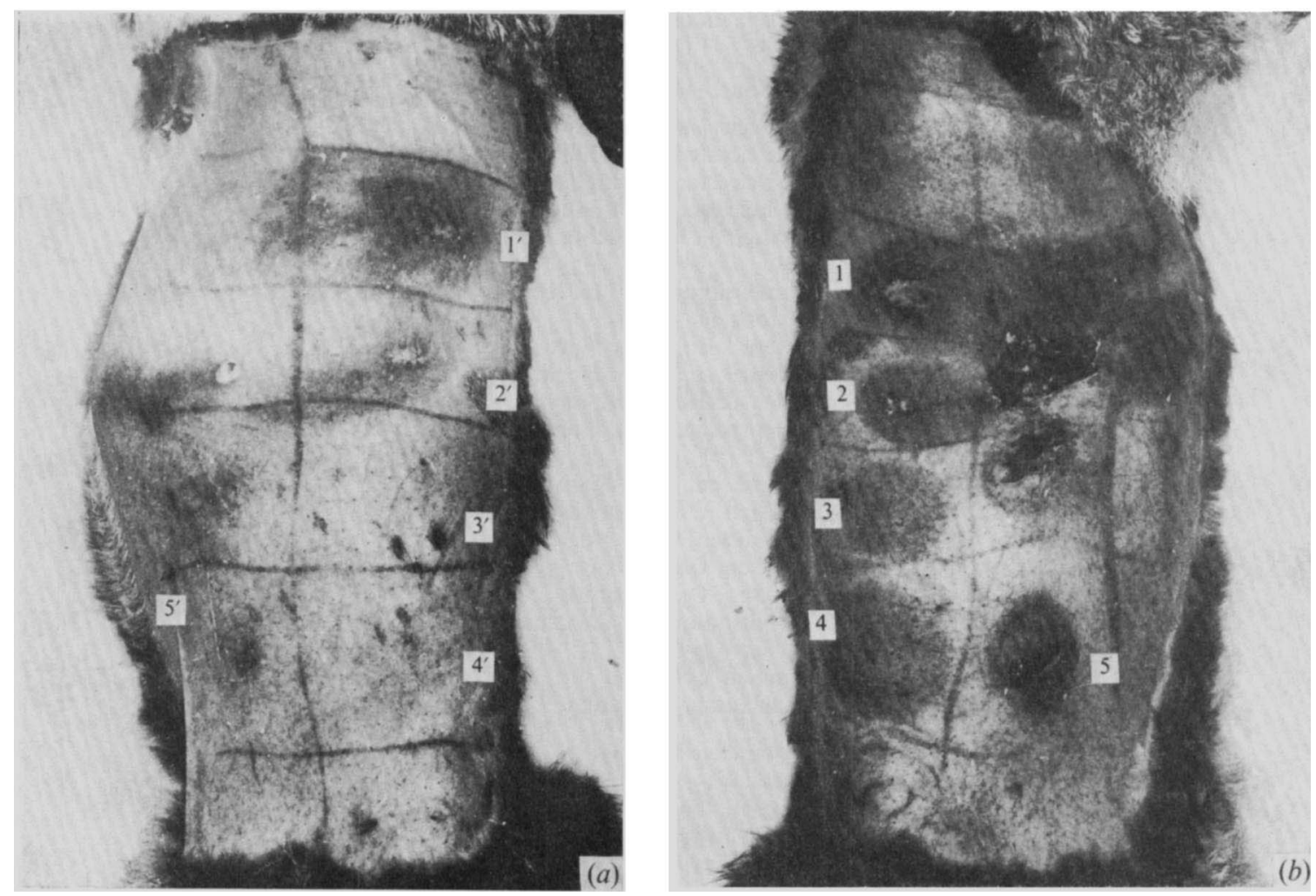

Fig. I. The skin test in rabbit (by Fraser method) of the filtrates of the Corynebacterium ovis 2 I (I) and C.O. $2 \mathrm{I}_{(76)}{ }^{\text {tox }}{ }^{+}(2,3,4)$, as compared with the diphtheria toxin (5). The filtrates were given before $(b)$ and after $(a)$ diphtheria antitoxin inoculation.

and converted with phage $\mathrm{W}$ and the diphtheria phages nos. 2, 20, $2 \mathrm{I}$ and 23. Strain C. ovis 20 produced Di-toxin (and was then labelled C.O. $2 \mathrm{I}_{(76)} \mathrm{Di}^{\text {tox }}{ }^{+}$) when phage 76 was used. Ditoxin in lysogenized $C$. ulcerans and $C$. ovis cultures was detected by all four techniques described under Methods. As would be expected, considerably smaller amounts of neutralizable diphtheria toxin appearing in filtrates of $\mathrm{Di}^{\text {tox }}{ }^{+}$cultures of C. ulcerans and C. ovis could be detected by assays in rabbit skin, in monkey kidney tissue cultures and in agar gel diffusion tests (see Figs. I to 3). Lysogenized strains of C. ulcerans and C. ovis retained their coccal morphology and ability to split urea and in addition to diphtheria toxin also produced their own specific toxins.

Corynebacterium ulcerans phage ' $h$ ' induced production of Di-toxin in two C. ulcerans strains ( 40 and $A 238$ ). However, when the ulcerans phages ' $b$ ' and ' $c$ ' were used to lysogenize the same strains no induction of diphtheria toxin resulted.

When widely phage-sensitive Corynebacterium diphtheriae strains such as $5056_{(-)}^{\text {tox }}{ }^{-1} C . D$. intermedius and $\mathrm{I030}_{(-)}{ }^{\text {tox }}{ }^{-} C$. belfanti were used, the ulcerans phages ' $\mathrm{b}$ ' and ' $\mathrm{h}$ ' lysogenized the strains and formed plaques. The ' $b$ ' phage, while lysogenizing, did not induce production of diphtheria toxin in strain $5056_{(-)}^{\text {tox }}{ }^{-}$C.D. intermedius, but phage ' $h$ ' converted strain $103 \mathrm{O}_{(-)}$tox $^{-} C$. belfanti to Di-toxigenicity without changing either its morphological or biochemical characteristics. 

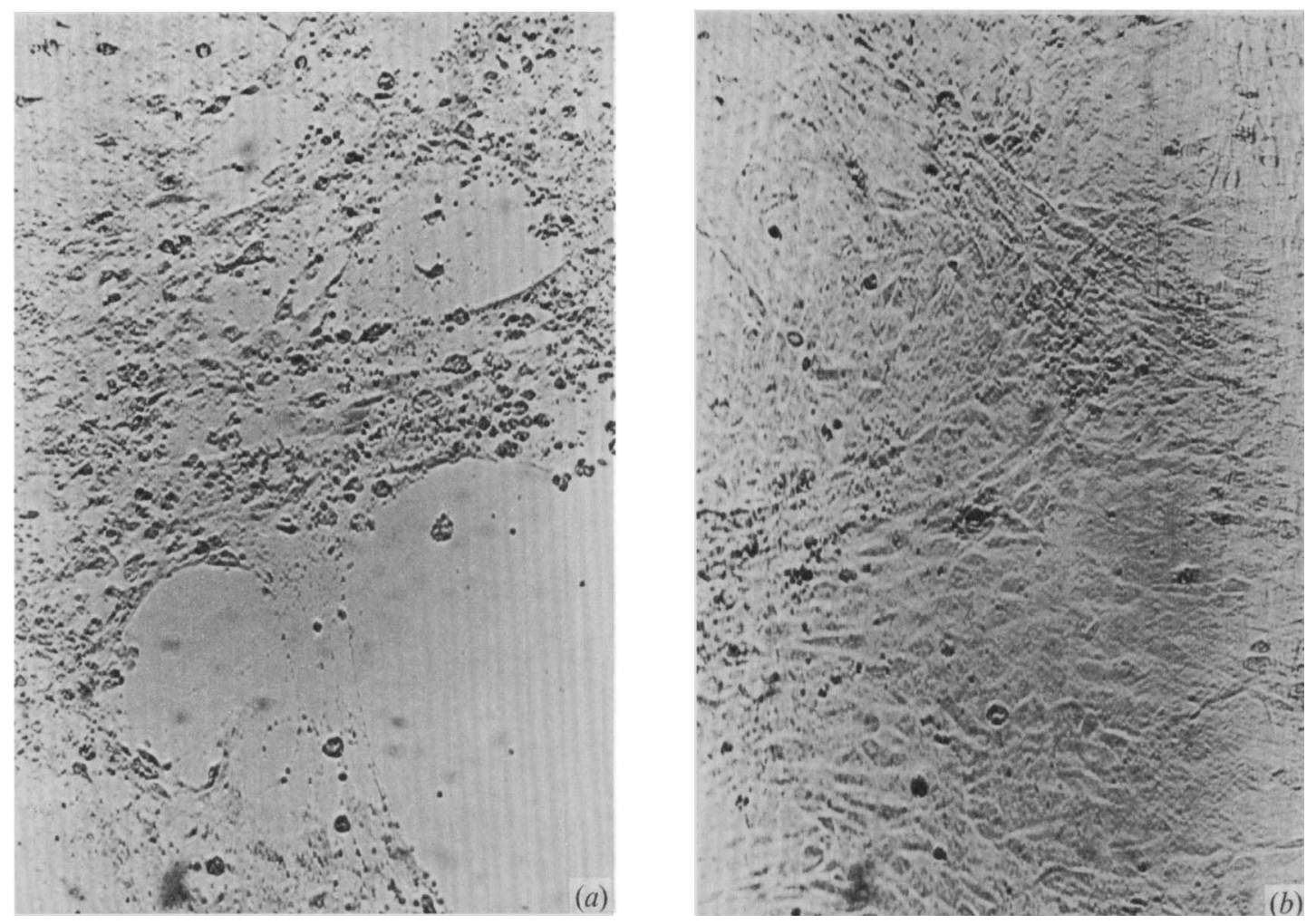

Fig. 2. Testing in monkey tissue culture of Di-tox ${ }^{+} C$. ovis 2 I culture. (a) Test, $(b)$ control. In the control tube the cytopathogenic effect was prevented by diphtheria antitoxin.

\section{Phage typing of C. ulcerans and C. ovis strains}

No specific pattern emerged and only few strains proved to be phage-sensitive when the standard set of diphtheria phages for typing Corynebacterium diphtheriae strains was used.

When the set of the six ulcerans phages ' $a$ ' to ' $h$ ' together with the diphtheria phage 76 restricted in Corynebacterium ovis strain no. $2 \mathrm{I}$ were used on 172 C. ulcerans and 62 C. ovis strains, a provisional phage-typing scheme consisting of 13 sensitivity patterns could be worked out (see Table 2). Strains from collections 20 years old were typed in this way. In man and horses some identical phage types were found (see Table 2).

The experiments established that: (i) All Corynebacterium ulcerans and C. ovis strains available to us could be phage-typed by this method (see Table 3 ). (ii) Only the widely phage-sensitive $C$. diphtheriae strains $5056_{(-)}$tox $^{-}$C.D. intermedius and $1030_{(-)}{ }^{\text {tox }}{ }^{-} C$. belfanti were sensitive to ulcerans phages. All other $C$. diphtheriae strains tested routinely were not susceptible to ulcerans phages. (iii) Phage types $A_{0}, I A, I_{2}, I V D, I V D_{1}, V E, V I G$ and $\mathrm{VIG}_{1}$ occurred only in C. ulcerans strains; phage types II $\mathrm{B}_{0}, \mathrm{IIB}_{1}$ and $\mathrm{VIG}_{2}$ were found only in $C$. ovis strains; phage type IIIC was present in both C. ulcerans and C. ovis strains (see Table I).

\section{Mouse pathogenicity test}

Contrary to the findings of Zaki (1966), in our hands only Corynebacterium ulcerans (five strains) produced arthritis in white mice. By contrast, $20 \mathrm{C}$. ovis strains administered intraperitoneally, intravenously or intracerebrally resulted in death of white mice. It was possible 
Table 2. Provisional phage-typing scheme for Corynebacterium ulcerans and C. ovis Pattern of sensitivity to phages

\begin{tabular}{|c|c|c|c|c|c|c|c|c|}
\hline $\begin{array}{l}\text { Host } \\
\text { strain }\end{array}$ & $\begin{array}{c}\text { (a) } \\
15542 / 238\end{array}$ & $\begin{array}{c}\text { (b) } \\
213 / 4 \mathrm{O}_{\mathrm{c}}\end{array}$ & $\begin{array}{c}\text { (c) } \\
\mathrm{I} 6259 / 4 \mathrm{O}_{\mathrm{c}}\end{array}$ & $\begin{array}{c}(d) \\
210 / 16 L\end{array}$ & $\begin{array}{c}(\mathrm{g}) \\
9304 / 984\end{array}$ & $\begin{array}{c}\text { (h) } \\
984 / 984\end{array}$ & $\begin{array}{c}(76) \\
76 c \text { ovis } 21\end{array}$ & $\begin{array}{l}\text { Phage } \\
\text { type }\end{array}$ \\
\hline \multicolumn{9}{|c|}{ C. ulcerans } \\
\hline 984 & $x$ & $x$ & $x$ & $\times$ & $x$ & $x$ & $x$ & $\mathbf{A}_{0}$ \\
\hline 9304 & $x$ & $x$ & $x$ & . & . & $x$ & $x$ & IA \\
\hline 5229 & $x$ & $x$ & $x$ & . & $x$ & . & $x$ & I $\mathbf{A}_{1}$ \\
\hline \multicolumn{9}{|c|}{ C. ovis } \\
\hline 996 & $x$ & $x$ & . & $\times$ & $x$ & $x$ & $x$ & II B $_{0}$ \\
\hline 990 & $x$ & $x$ & . & $\times$ & . & $x$ & $x$ & II B $_{1}$ \\
\hline \multicolumn{9}{|c|}{ C. ulcerans } \\
\hline 16259 & $x$ & $x$ & . & 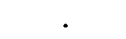 & . & $x$ & $x$ & II B $_{2}$ \\
\hline $16 \mathrm{~L}$ & $x$ & $x$ & . & $x$ & $x$ & . & . & IIIC \\
\hline $2 \mathrm{IOL}$ & $x$ & $x$ & . & . & . & . & . & IVD \\
\hline $318 c$ & $x$ & $x$ & . & . & . & . & . & IVD $D_{1}$ \\
\hline $213 \mathrm{~L}$ & $x$ & . & . & $x$ & $x$ & . & . & VE \\
\hline 15542 & . & $x$ & . & . & . & . & . & VIG \\
\hline 4870 & . & $x$ & . & $\times$ & . & . & . & $\mathrm{VIG}_{1}$ \\
\hline \multicolumn{9}{|c|}{ C. ovis } \\
\hline $02 \mathrm{I}$ & . & $x$ & . & . & . & . & $x$ & $\mathrm{VIG}_{2}$ \\
\hline
\end{tabular}

Table 3. Analysis of Corynebacterium ulcerans and C. ovis strains according to phage types

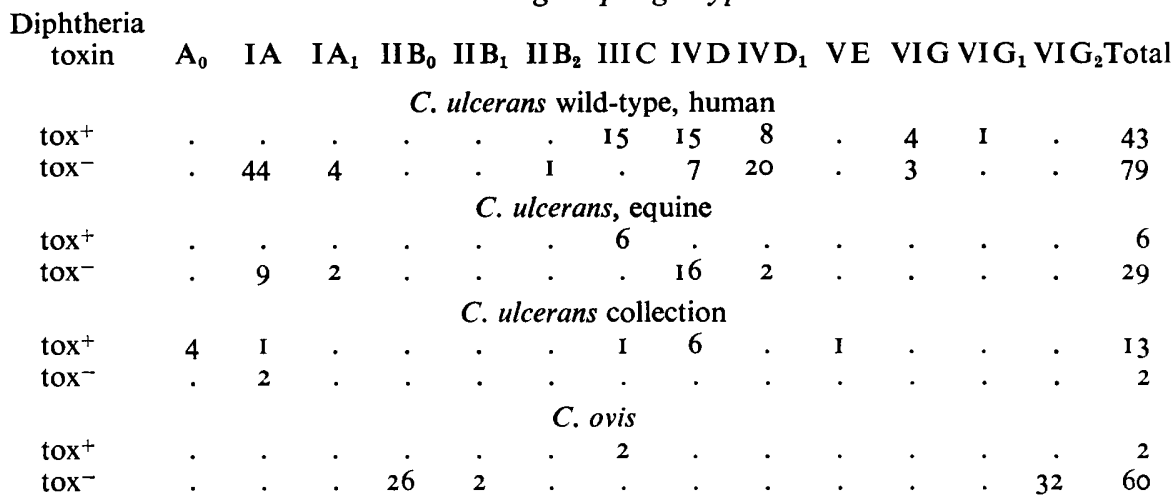

in this way to establish that the two strains Bov I (992) and Bov 2 (993) isolated from buffaloes in Egypt have to be regarded as C. ovis. Both these strains were found by us to be $\mathrm{Di}$ toxigenic and to belong to phage type IIIC.

Epidemiological implications of phage-typing of C. ulcerans and C. ovis strains, both wild-type and collection strains

Of the I 57 wild-type Corynebacterium ulcerans strains isolated, 3 I $2 \%$ were Di-toxigenic and in four cases of human tonsillitis the serum level of diphtheria antitoxin of $0.2 \mathrm{i}$.u. was adequate for protection against diphtheria toxin. Most strains isolated from man occurred in carriers, mostly children in rural areas, and only rarely was a sore throat or tonsillitis present. When the studies of Stănică et al. (I968) were extended it was found that $50 \%$ of horses 


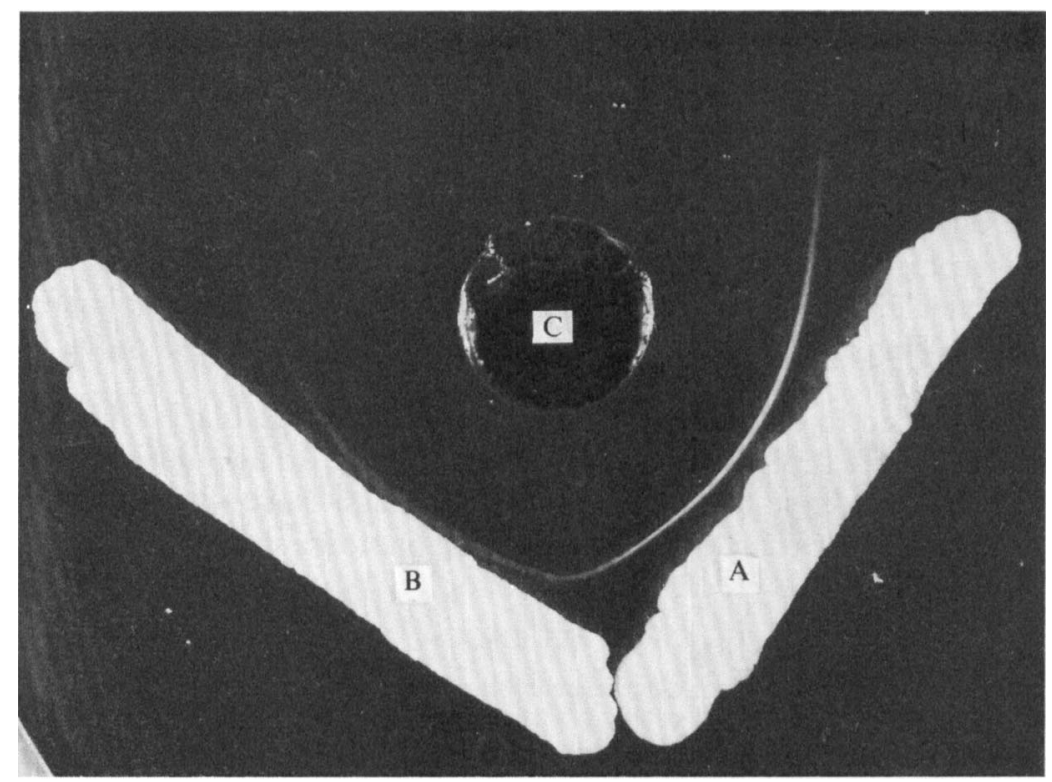

Fig. 3. Gel-immuno-diffusion of toxin produced by Corynebacterium diphtheriae Park Williams No. 8 strains (Weissensee) (A) and Co I I $_{3(w)}{ }^{t o x}+$ (B) against purified diphtheria antitoxin (C).

investigated carried $C$. ulcerans. Among wild $C$. ulcerans strains, ten were non-starchfermenting and belonged to different phage types, but four were similar to those of Mair u. 26.348 and W. H. H. Jebb no. 2 non-starch-fermenting.

Strain C.O. $2 \mathrm{I}_{(76)} \mathrm{Di}^{\text {tox }}{ }^{+}$produced an accidental laboratory skin infection in one of us. Local and general symptoms were recorded and the Di-tox ${ }^{+}$Corynebacterium ovis strain was isolated from the lesion.

\section{DISCUSSION}

The demonstration of phage-induced diphtheria toxin production in Corynebacterium ulcerans and $C$. ovis raises two questions. How far is it justified to consider diphtheria toxin to be an attribute only of the diphtheria species? What importance is attached to the capacity to produce diphtheria toxin in the characterization of C.D. species?

Corynebacterium ovis is known to differ sharply from $C$. diphtheriae by producing a filterable toxin which differs fundamentally from that of $C$. diphtheriae, although C. ulcerans and $C$. ovis share in common with this species characters recognized as biotypes.

The problems which arise are how much these species differ from each other (if it is justified to regard Corynebacterium ulcerans and C. ovis as species) and what causes the Di-tox $^{+}$gene to be expressed as a common character in such different hosts.

The present experiments confirm Howard \& Jann's (1954) findings about the lack of activity of $C$. ulcerans phages on strains of $C$. diphtheriae and this favours Henriksen's (I955) view that $C$. ulcerans is a separate species of Corynebacterium.

However, in our experiments Corynebacterium ulcerans phages were able to form plaques in a few $C$. diphtheriae strains, but only in those strains possessing a wide phage-sensitivity. Our work raises yet another unanswered question, namely, do $C$. ulcerans strains carry both ulcerans and diphtheria phages?

Our earlier findings (Maximescu et al. 1968) on diphtheria toxin induction in C. ovis which 
lead to the proof that the gene tox ${ }^{+}$can be expressed in Corynebacteria other than $C$. diphtheriae, has been accepted (Barksdale, 1970). The present results confirm that the Ditox ${ }^{+}$character may be more widely induced among species of the genus Corynebacterium. From this, the question arises: is the genetically determined capacity to produce diphtheria toxin dependent also on the host bacterial cell, or only on the phage type inducing the production of diphtheria toxin?

Since these problems require further investigation, it seems possible that some of our findings, in particular the distinction between Corynebacterium ulcerans and $C$. ovis by means of phage typing and the mouse pathogenicity test, may prove of value.

Thanks are extended to our colleagues from the Romanian Public Health Laboratories. We are most indebted to Professor K. S. Zinnemann, Leeds, for help in reviewing the manuscript. We thank Elena Vieru for her tireless technical assistance with several parts of this work and V. Ganed and Delia Dragomir for taking photographs.

\section{REFERENCES}

AfNan, M. (1969). Hemolysis activity of Corynebacterium ovis. Veterinary Recorder 84, 563.

Battey, Y. M., Tonge, J. I., Horsfall, W. R. \& McDonald, I. R. (1968). Human infection with Corynebacterium ovis. Medical Journal of Australia 2, 540-543.

BarksDale, L. (1970). Corynebacterium diphtheriae and its relatives. Bacteriological Reviews 34, 378-422.

Calalb, G., Stǎnică, E., Maximescu, P., Stoian, C. \& Stoian, I. (1965). Toxigénèse chez Corynebacterium diphtheriae, mise en évidence par la méthode des cultures de tissus. Archives roumaines de pathologie expérimentale et de microbiologie $24,7 \mathrm{I}-76$.

CARNE, H. R. (1968). Action of bacteriophages obtained from Corynebacterium diphtheriae, on C. ulcerans and C. ovis. Nature, London 217, 1066-1067.

FRASER, D. T. (193I). A technique for quantitative determination of diphtheria antitoxin in rabbits. Transactions of the Royal Society of Canada (S 5) 25, 175-181.

HeNRIKSEN, S. D. (1955). Some bacteriophages of C. ulcerans and their lack of effect on toxigenicity. Acta pathologica et microbiologica scandinavica 37, 65-70.

HowARD, D. H. \& JANN, G. H. (1954). The isolation and characterization of bacteriophage active against the diphtheria-like Corynebacteria. Journal of Bacteriology 68, 316-319.

JEBB, W. H. H. (1948). Starch-fermenting gelatin liquefying Corynebacterium isolated from human nose and throat. Journal of Pathology and Bacteriology 60, 403-4I2.

JEBB, W. H. H. \& MARTIN, T. D. (1965). A non-starch-fermenting variant of $C$. ulcerans. Journal of Clinical Pathology 18, 757-758.

MaXimescu, P. (1967). Corynebacterium ulcerans. Microbiologia, Parazitologia, Epidemiologia (Bucharest) I2, 355-360.

Maximescu, P. (1968). New host-strains for the lysogenic Corynebacterium diphtheriae Park Williams no. 8 strain. Journal of General Microbiology 53, I25-I 33.

Maximescu, P. \& DrăgoI, T. (197I). Examen in vitro de la toxigénicité de Corynebacterium diphtheriae. Nouvelle modification du test d'Elek-Ouchterlony. Archives roumaines de pathologie expérimentale et de microbiologie 30, 493.

MaXimescu, P., PoP, A., OPRişAn, A. \& PotoraC, E. (1968). Relations biologiques entre C. ulcerans, C. ovis et $C$. diphtheriae. Étude expérimentale. Archives roumaines de pathologie expérimentale et de microbiologie 27, 733-750.

NARbutovicz, B. (1955). Studies on the variability of $C$. diphtheriae induced by phage. Acta microbiologica polonica 4, 245-264.

SARAGEA, A. \& MAXIMESCu, P. (1964). Schéma provisoire de lysotypie chez $C$. diphtheriae. Archives roumaines de pathologie expérimentale et de microbiologie 23, 817-838.

Stănică, E., Maximescu, P., Stolan, C., Pop, A., Oprişan, R. \& Potorac, E. (I968). Niveau de l'immunité antitoxique et le portage de bacilles diphtériques chez les chevaux dans le stade de diminution de la morbidité par la diphtérie. Archives roumaines de pathologie expérimentale et de microbiologie 27, 555-562.

ZAKI, M. M. (1966). The ability of C. ovis to produce suppurative osteomyelitis and arthritis in white mice. Journal of Comparative Pathology 76, 121-126. 